\title{
Sulfonation degree effect on ion-conducting SPEEK-titanium oxide membranes properties
}

\author{
Jacqueline Costa Marrero ${ }^{1 *}$, Ailton de Souza Gomes ${ }^{1}$, Wang Shu Hui², José Carlos Dutra Filho' and \\ Vivianna Silva de Oliveira ${ }^{3}$
}

\section{${ }^{1}$ Instituto de Macromoléculas Professora Eloisa Mano - IMA, Universidade Federal do Rio de Janeiro - UFRJ, Rio de Janeiro, RJ, Brazil \\ ${ }^{2}$ Departamento de Engenharia Metalúrgica e de Materiais, Escola Politécnica, Universidade de São Paulo - USP, São Paulo, SP, Brazil}

${ }^{3}$ Escola Técnica Rezende Rammel - ETRR, Rio de Janeiro, RJ, Brazil

*jacquecosta@gmail.com

\begin{abstract}
Polymeric membranes were developed using a SPEEK (sulfonated poly(ether ether ketone)) polymer matrix, containing titanium oxide $\left(\mathrm{TiO}_{2}\right.$ ) (incorporated by sol-gel method). SPEEK with different sulfonation degrees (SD): $63 \%$ and $50 \%$ were used. The influence of sulfonation degree on membrane properties was investigated. The thermal analysis (TGA and DTGA) and X-ray diffraction (XRD) were carried out to characterize the membranes and electrochemical impedance spectroscopy (EIS) was carried out to evaluate the proton conductivity of the membranes. The proton conductivities in water were of 3.25 to $37.08 \mathrm{mS} . \mathrm{cm}^{-1}$. Experimental data of impedance spectroscopy were analyzed with equivalent circuits using the Zview software, and the results showed that, the best fitted was at $80{ }^{\circ} \mathrm{C}$.
\end{abstract}

Keywords: membrane, sulfonation degree, SPEEK.

\section{Introduction}

Polymer electrolyte membrane fuel cells (PEMFCs) are considered as the most promising fuel cell technology for a wide range of applications due to the stable operation, the high energy generation yield and the simplicity of the system $^{[1]}$.

The polymer electrolyte membranes (PEMs) has gain considerable attention due to its applications in many energy related fields such as water electrolyzers, fuel cells, battery systems, etc. The function of the membrane in PEM fuel cells is two fold: proton conduction from the anode to the cathode, and effective separation of the anode and cathode gases $^{[2]}$. PEMs exhibit several advantages over liquid or solid inorganic electrolytes. The polymeric membrane should satisfy several requirements: high proton conductivity, good chemical, thermal and mechanical stability, and low permeability to reactants. Low cost and ready availability are important economical requirements. Furthermore, the membrane should work at an operative temperature around $120{ }^{\circ} \mathrm{C}$ for long time ${ }^{[1,3]}$.

The poly(ether ether ketone) (PEEK) is one polymer with good characteristics: excellent chemical resistance, high thermo-oxidative stability and low $\operatorname{cost}^{[4]}$. Sulfonated poly(ether ether ketone is obtained by sulfonation of PEEK by concentrated sulfuric acid. The SPEEK offers the advantages of lower cost, easier preparation, controllable proton conductivity and excellent chemical and thermal stability $^{[5]}$. The chemical structure of PEEK and SPEEK are shown in Figure 1.

Sulfonation is a powerful method for the modification of polymers to introduce sulfonic acid functionality, which aids in the transport of protons. It makes the polymer hydrophilic and hence increases the solubility of polymers ${ }^{[7]}$. Higher sulfonation degree can enhance the density of acid sites and facilitate the proton transport. Therefore, there exists a conflict between high SD and poor mechanical strength of SPEEK membrane ${ }^{[8]}$. In order to enhance its competitive superiority in PEMFC application, varied efforts were made to modify the structure-property relationship of SPEEK. Incorporation of nanosized binary oxide materials $\left(\mathrm{SiO}_{2}, \mathrm{TiO}_{2}, \mathrm{ZrO}_{2}\right)$ in SPEEK membranes has several attributes of interest, including decreased membrane swelling, reduced permeability towards methanol and improved morphological stability without compromising proton conductivity at high degree of sulfonation ${ }^{[9]}$.
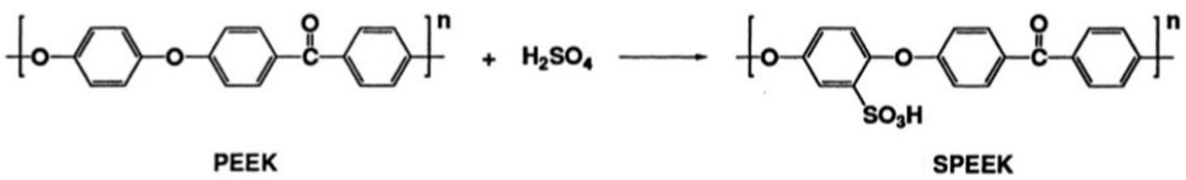

SPEEK

Figure 1. Chemical structures of PEEK and SPEEK ${ }^{[6]}$. 
In this study, composite membranes using SPEEK (with different sulfonation degrees (63 and 50\%)) and titanium oxide were prepared and characterized by TGA and DTGA, XRD and EIS to evaluating the influence of sulfonation degree in the structure, thermal properties and ionic conduction of the membranes.

\section{Materials and Methods}

\subsection{Sulfonation of PEEK}

$10 \mathrm{~g}$ of PEEK (Victrex ${ }^{\mathrm{TM}}$ USA Inc) was dissolved in $200 \mathrm{ml}$ of sulfuric acid $\left(\mathrm{H}_{2} \mathrm{SO}_{4}\right)$ (VETEC Química Fina LTDA) under nitrogen atmosphere. The mixture was stirred at $30{ }^{\circ} \mathrm{C}$ for $4 \mathrm{~h}$. To follow the reaction, the mixture was stirred at $50{ }^{\circ} \mathrm{C}$ for $5 \mathrm{~h}$. The sulfonation reaction was terminated by precipitating the acidic polymer solution into a large excess of ice-cold water under continuous mechanical stirring. The polymer precipitate was washed several times with deionized water until the $\mathrm{pH}$ was neutral. The polymer was dried under vacuum for $24 \mathrm{~h}$ at $70{ }^{\circ} \mathrm{C}$. The same procedure was done with the difference that the mixture was stirred at $30{ }^{\circ} \mathrm{C}$ for $4 \mathrm{~h}$ and after that the mixture was stirred at $50{ }^{\circ} \mathrm{C}$ for $4 \mathrm{~h}$ to obtain different sulfonation degree.

\subsection{Determination of the ion-exchange capacity (IEC) and $S D$}

The IEC and SD of SPEEK was determined by titration method with $\mathrm{NaOH}$ solution and phenolphthalein, using the following equations:

$$
\begin{aligned}
& I E C=\frac{\text { Volume of } \mathrm{NaOH} x \text { molar concentration of } \mathrm{NaOH}}{\text { Weight of SPEEK }} \\
& S D=\frac{M_{p} \times I E C}{1000-\left(M_{S O 3 H} \times I E C\right)}
\end{aligned}
$$

where $M_{P}=288 \mathrm{~g} \mathrm{~mol}^{-1}$ and $M_{\text {SOзH }}=80 \mathrm{~g} \mathrm{~mol}^{-1}$ are the molecular weights of the monomer unit of the polymer and of a sulfonic group, respectively.

The measured IEC average value (after three measurements) for SPEEK was: $1.87 \mathrm{meq}^{-1}$ corresponding to an SD of 63\% (SPEEK 63\%) and $1.52 \mathrm{meq}^{-1}$ corresponding to an SD of $50 \%$ (SPEEK $50 \%$ ).

\subsection{Membranes preparation}

Membranes were prepared using the sol-gel process. For membrane preparation, the SPEEK $63 \%$ polymer was dissolved in NMP (1-Methyl-2-pyrrolidone) (VETEC Química Fina LTDA). After complete polymer dissolution, the solution was placed to cool. After that, acetylacetone (ACAC) (Aldrich Chemical Co) and titanium oxide ( $4 \mathrm{wt} \%$ ) were added to the polymer solution and was stirred for $1 \mathrm{~h}$. The amount of titanium alkoxide was calculated to produced samples containing $96: 4 \mathrm{wt} \% \mathrm{SPEEK} / \mathrm{TiO}_{2}$ rations using Titanium tetrabutoxide $\left(\left(\mathrm{Ti}_{2}\left(\mathrm{C}_{4} \mathrm{H}_{9} \mathrm{O}\right)_{4}\right)\right.$ or $\left.\left(\mathrm{Ti}(\mathrm{OBu})_{4}\right)\right)$ (MERCK-Schuchardt). ACAC was used as a chelating agent to avoid precipitation of the inorganic compound. The mixtures were cast on glass plates heated to $70^{\circ} \mathrm{C}$ for solvent evaporation. After casting, the membranes were stored in a vacuum oven for $72 \mathrm{~h}$ at $80{ }^{\circ} \mathrm{C}$. The membranes from SPEEK $50 \%$ were prepared by the same technique described.

\subsection{X-ray diffraction $(X R D)$}

XRD patterns of dry membranes were recorded in the $2 \theta$ range $2-80^{\circ}$ at a scan rate of $0.022 \theta / \mathrm{s}$ with Rigaku Miniflex II X-ray diffractometer, using $\mathrm{CuK} \alpha(\lambda=1.54 \AA)$ radiation.

\subsection{Thermal analysis (TGA and DTGA)}

Thermal gravimetric studies (TGA/DTGA) were performed in a TA TGA Q500 in the temperature range between 30 and $700{ }^{\circ} \mathrm{C}$ at a heating rate of $10{ }^{\circ} \mathrm{C} / \mathrm{min}$ and carried out under nitrogen flow $60 \mathrm{~mL} / \mathrm{min}$.

\subsection{Electrochemical impedance spectroscopy (EIS)}

The proton conductivity of membranes was measured using electrochemical impedance spectroscopy with an Autolab PGSTAT-30 potentiostat/galvanostat instrument, in the frequency range of $1 \mathrm{MHz}$ to $10 \mathrm{~Hz}$ and amplitude of $5 \mathrm{mV}$, using two stainless steel blocking electrodes and the contact area of $0.1 \mathrm{~cm}^{2}$. The measurements were done in the normal direction to the plane of the membranes, with samples immersed in deionized water at different temperatures $\left(30,50\right.$ and $\left.80^{\circ} \mathrm{C}\right)$.

The resistance value associated to membrane conductivity was determined from the high frequency intercept of the impedance with the real axis ( $\left.Z^{\prime}\right)$ and was called $\mathrm{R}_{\mathrm{S}(\text { exp.) }}$. The proton conductivity $(\sigma)$ was calculated from the impedance data according to Equation 3:

$$
\sigma=\frac{L}{R S}
$$

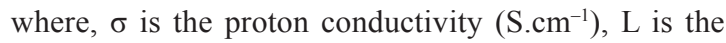
membrane thickness $(\mathrm{cm}), \mathrm{R}$ is the measured membrane resistivity $(\mathrm{Ohm})$ and $\mathrm{S}$ is the electrode area perpendicular to current flow $\left(\mathrm{cm}^{2}\right)$.

Experimental data have been fitted with the Randles equivalent circuit (Figure 2) using the Zview software. In this software an equivalent circuit is assembled which generates a theoretical curve, adjusted to experimental measurements, thus, we obtain the values of the circuit elements. A Randles circuit is an equivalent electrical circuit

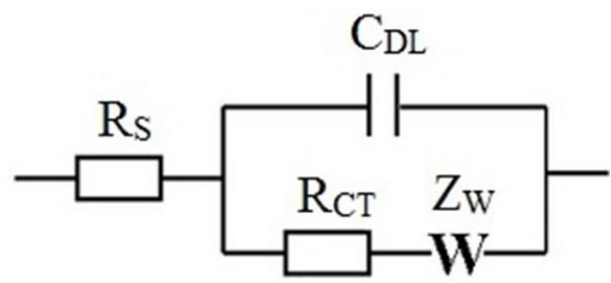

Figure 2. The Randles equivalent circuit ${ }^{[10]}$. The Randles parameters are $\mathrm{R}_{\mathrm{S}}$ (active electrolyte resistance); $\mathrm{C}_{\mathrm{DL}}$ (double-layer capacitance); $\mathrm{R}_{\mathrm{CT}}$ (active charge transfer resistance) and $\mathrm{Z}_{\mathrm{W}}$ (Warburg impedance). 
that consists of an active electrolyte resistance $R_{S}$ in series with the parallel combination of the double-layer capacitance $\mathrm{C}_{\mathrm{DL}}$ and an impedance of a faradic reaction. The impedance of a faradic reaction consists of an active charge transfer resistance $R_{C T}$ and a specific electrochemical element of diffusion $\mathrm{W}$, where $\mathrm{Z}_{\mathrm{W}}$ is the Warburg impedance (the first distributed element (DE) introduced into electrochemistry $)^{[10]}$.

The electrolyte resistance, the double-layer capacitance, the charge transfer resistance and the Warburg impedance were obtained by fitting the impedance spectra using the equivalent circuit and software Zview. The electrolyte resistance obtained by fitting the experimental data was called $\mathrm{R}_{\mathrm{S}(\text { sim.) }}$ and was compared with $\mathrm{R}_{\mathrm{S}(\text { exp.) }}$. When use the Circuit of Figure 2 and the software Zview to simulate the experimental impedance spectrum, appears $\mathbf{Z}_{\mathbf{w}(1-R)}, \mathbf{Z}_{\mathbf{w}_{(1-T)}}$ and $\mathbf{Z}_{\mathbf{w}(1-\mathrm{P})}$, where 1 means the distributed element type (of 11 available) and R, T, P are free parameters which have different meanings for each DE type; in general they use the following convention: $\mathrm{R}$ - Usually resistance, $\mathrm{T}$ - A time constant or capacitance and $\mathrm{P}$ - an exponent ${ }^{[11]}$.

\section{Results and Discussions}

X-ray diffraction patterns of membranes are presented in Figure 3. The membranes are fully amorphous: a broad diffraction peak at $2 \theta$ around of $20^{\circ}$ is indicative of the lack of crystallinity. The amorphous nature of membranes indicates SPEEK with medium and high SD, in this case 63 and $50 \%{ }^{[7]}$. The introduction of $\mathrm{SO}_{3} \mathrm{H}$ groups into the PEEK alters the chain conformation and packing, and thus causes loss of crystallinity. It is know that the amorphous nature of membranes imparts easier mobility of polymer chains which accounts for faster proton exchange resulting in higher proton conductivity of membranes.

The results of thermogravimetric analysis and the differential thermogravimetric analysis of prepared membranes are shown in Figure 4. The first weight loss around $100{ }^{\circ} \mathrm{C}$ can be attributed to water molecules adsorbed by hydrophilic groups and lost until the dry state of the sample is reached ${ }^{[9]}$. The second weight loss between $100{ }^{\circ} \mathrm{C}$ and $400{ }^{\circ} \mathrm{C}$ is attributed to loss of residual solvent NMP and the decomposition of the sulfonic acid groups of SPEEK. The decomposition of the polymer matrix was from $400{ }^{\circ} \mathrm{C}$ to $700{ }^{\circ} \mathrm{C}$.

The exothermic peaks, which corresponds to the water loss and the decomposition of the sulfonic groups, are more intense for $\mathrm{SPEEK} 63 \%$ - $\mathrm{TiO}_{2}$, with higher $\mathrm{SD}$, because the water amount is associated to the sulfonic groups, the peak intensity increases with the increase of sulfonation degree ${ }^{[12]}$.

AC impedance spectroscopy was performed to determine the conductivity of these membranes. The variation of conductivity with temperature for the different composite
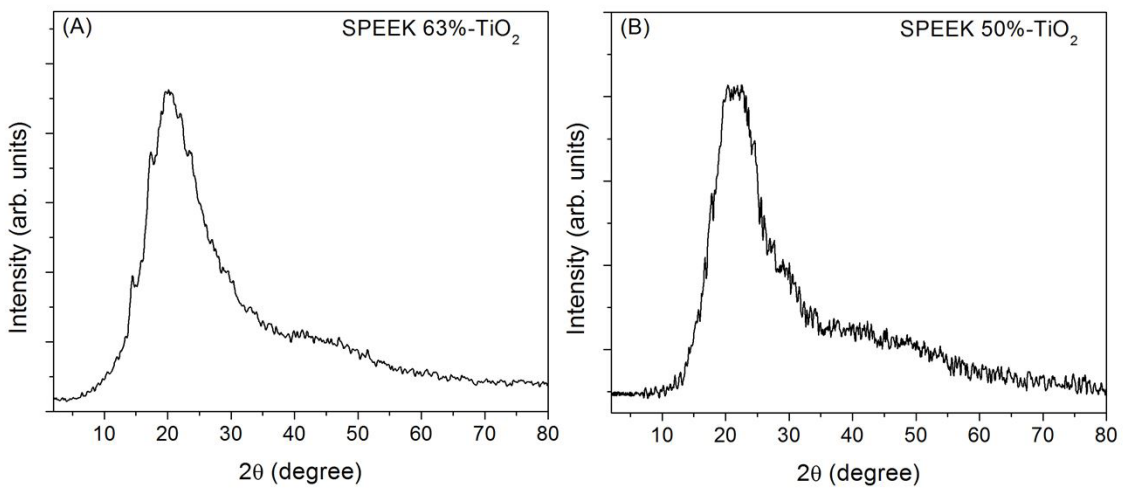

Figure 3. XRD patterns of membranes: (A) SPEEK 63\%- $\mathrm{TiO}_{2}$ and (B) SPEEK 50\%- $\mathrm{TiO}_{2}$.
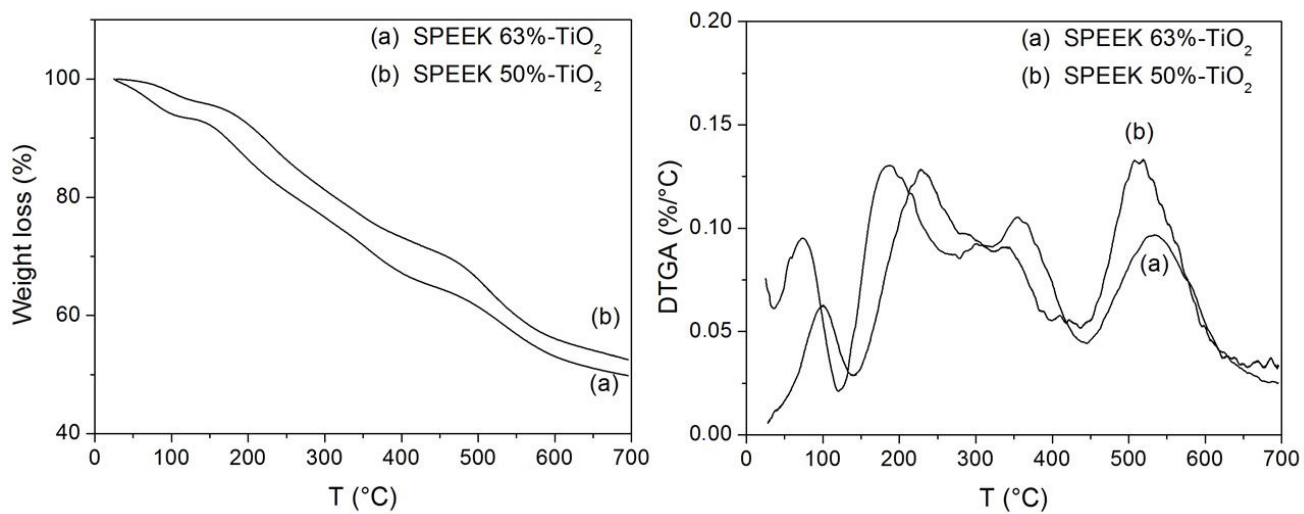

Figure 4. Thermal analysis (TGA and DTGA) of SPEEK 63\%- $\mathrm{TiO}_{2}$ and SPEEK 50\%- $\mathrm{TiO}_{2}$ membranes. 
membranes is shown in Figure 5. The Arrhenius plots of the temperature dependency of the conductivity exhibit that the conductivity increases with temperature. Proton conductivity data for studied membranes are presented in Table 1. In the hydrated composite membranes the proton conduction is likely to happen by vehicular mechanism, rather than by Grotthuss mechanism, resulting in a long-range conductivity, with protons percolating through the sample ${ }^{[2]}$.

Di Vona et al. ${ }^{[3]}$ have reported the preparation of hybrid membranes based on highly sulfonated poly(ether ether ketone) (SPEEK, SD = 0.9) where titanium oxide network was dispersed by in situ sol-gel reactions. They obtained membranes with enhanced thermal stability, reduced water uptake and good proton conductivity $\left(\sigma=58.00 \mathrm{mS} . \mathrm{cm}^{-1}\right)$ up to $120^{\circ} \mathrm{C}$ and concluded that the samples were suitable for application as polymeric electrolytes at intermediate temperature. Dutra et al. ${ }^{[13]}$ also reported the proton-conducting of hybrid membranes consisting of SPEEK and titanium oxide, the proton conductivity in ethanol solution was of the order of $10^{-3} \mathrm{~S}^{-\mathrm{cm}^{-1}}$ when 4 or $8 \mathrm{wt} \% \mathrm{TiO}$, were added, and generally increased with addition of $\mathrm{TiO}_{2}$. In this study, the membranes showed conductivity values in the range $3.25-37.08 \mathrm{mS} . \mathrm{cm}^{-1}$. A maximum conductivity of $37.08 \mathrm{mS}^{-\mathrm{cm}^{-1}}$ was obtained for the SPEEK $63 \%-\mathrm{TiO}_{2}$ membranes at $80{ }^{\circ} \mathrm{C}$. For all studied temperatures, the SPEEK $63 \%$ - $\mathrm{TiO}_{2}$ membranes with $\mathrm{SD}=63 \%$ showed higher conductivity than the SPEEK 50\%- TiO membranes with $\mathrm{SD}=50 \%$, as expected. Proton transfer enhances by increasing the number of acid sites enhances the proton transfer.

The impedance characteristics of the SPEEK $63 \%$ - $\mathrm{TiO}_{2}$ and SPEEK 50\%- $\mathrm{TiO}_{2}$ membranes under different operating temperatures $\left(30,50\right.$ and $\left.80{ }^{\circ} \mathrm{C}\right)$ were also investigated.

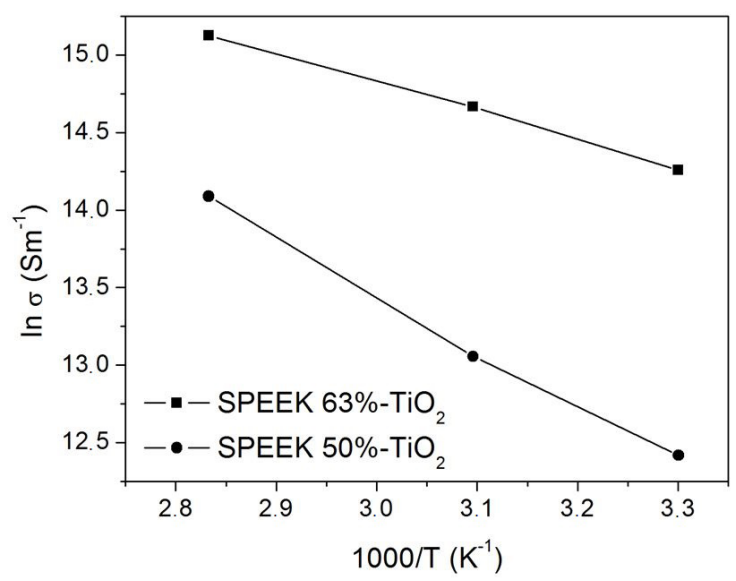

Figure 5. Arrhenius plots for the proton conductivity of the membranes as a function of temperature.

Table 1. Proton conductivity values of the membranes.

\begin{tabular}{|c|c|c|}
\hline \multirow[b]{2}{*}{$\mathrm{T}\left({ }^{\circ} \mathrm{C}\right)$} & \multicolumn{2}{|c|}{ Conductivity (mS.cm $\left.{ }^{-1}\right)$} \\
\hline & ${\text { SPEEK } 63 \%-\mathrm{TiO}_{2}}_{2}$ & SPEEK 50\%-TiO \\
\hline 30 & 15.55 & 3.25 \\
\hline 50 & 23.42 & 4.68 \\
\hline 80 & 37.08 & 13.14 \\
\hline
\end{tabular}

The result was plotted as a Cole-Cole plot to show the real/imaginary parts of the impedance at various frequencies.

A typical Nyquist plot of a composite membrane sandwiched stainless steel electrodes is shown in Figure 6 for SPEEK 50\%- $\mathrm{TiO}_{2}$ membranes (similar result were obtained for SPEEK 63\%- $\mathrm{TiO}_{2}$ membranes). The profile shows that the impedance decreases with increasing frequency. It indicates that the interfacial impedance decreases with increasing frequency, which can be attributed to double layer formation and charge transfer reaction.
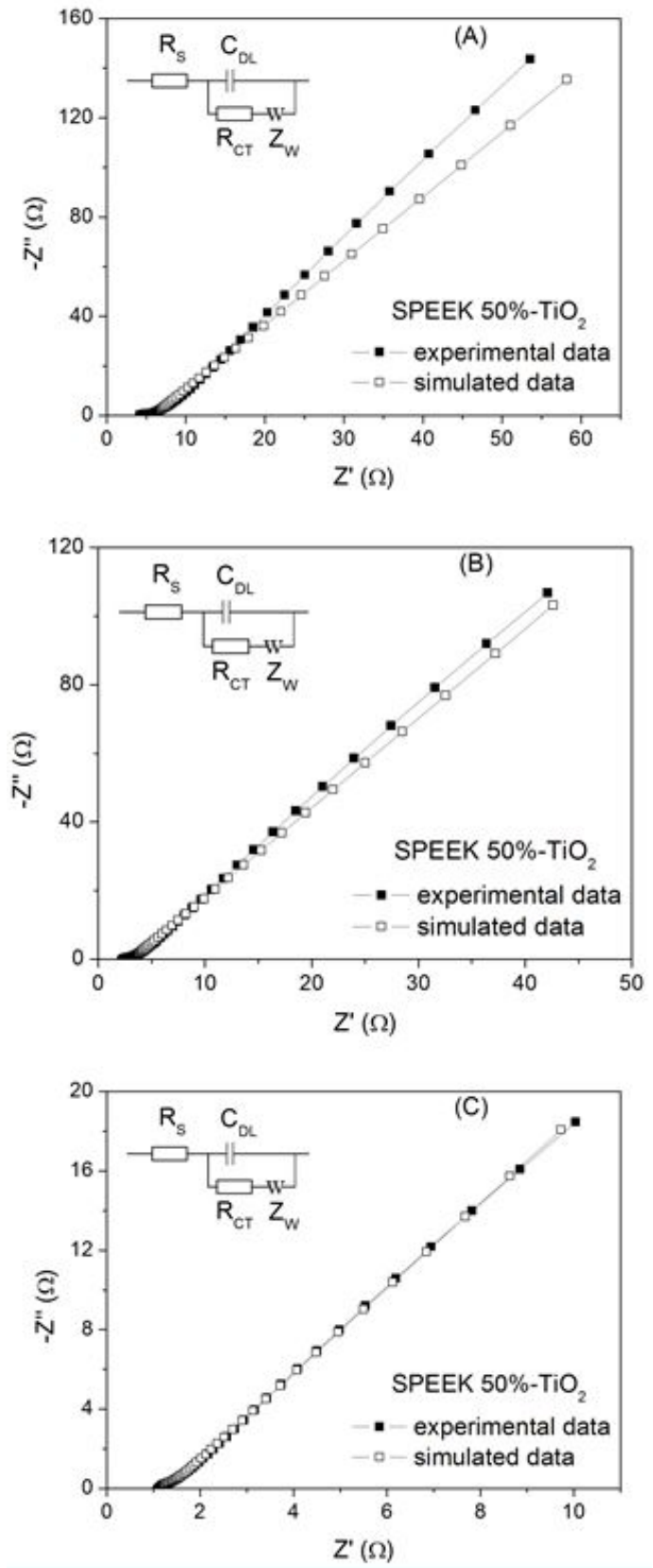

Figure 6. Nyquist plots of the SPEEK $50 \%$ - $\mathrm{TiO}_{2}$ membrane for experimental impedance spectrum and simulated impedance spectrum (using the Randles equivalent circuit and the Zview software) for: (A) $\mathrm{T}=30{ }^{\circ} \mathrm{C}$; (B) $\mathrm{T}=50^{\circ} \mathrm{C}$; (C) $\mathrm{T}=80{ }^{\circ} \mathrm{C}$. 
Table 2. $\mathrm{R}_{\text {S(exp.) }}$ obtained from the experimental impedance spectrum and circuit parameters used to simulated the impedance spectrum. The Randles parameters are $\mathrm{R}_{\mathrm{S}(\exp .)}$ (active electrolyte resistance experimental), $\mathrm{R}_{\mathrm{S}(\text { sim.) }}$ (electrolyte resistance obtained by fitting the experimental), $\mathrm{C}_{\mathrm{DL}}$ (double-layer capacitance), $\mathrm{R}_{\mathrm{CT}}$ (active charge transfer resistance) and $\mathrm{Z}_{\mathrm{W}}$ (Warburg impedance), where $\mathbf{Z}_{\mathrm{w}(1-\mathrm{R})}, \mathbf{Z}_{\mathrm{w}(1-\mathrm{T})}$ and $\mathbf{Z}_{\mathbf{w ( 1 - P )}}$ and 1 means the distributed element type (of 11 available) and R, T, P are free parameters which have different meanings for each distributed elements type; in general they use the following convention: R - Usually resistance, $\mathrm{T}$ - A time constant or capacitance and $\mathrm{P}$ - an exponent.

\begin{tabular}{|c|c|c|c|c|c|c|}
\hline \multirow[b]{2}{*}{$\mathrm{T}\left({ }^{\circ} \mathrm{C}\right)$} & \multicolumn{3}{|c|}{ SPEEK 63\%-TiO } & \multicolumn{3}{|c|}{ 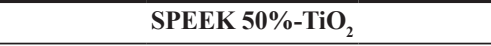 } \\
\hline & 30 & $\mathbf{5 0}$ & 80 & 30 & 50 & 80 \\
\hline $\mathbf{R}_{\mathrm{S}(\text { exp.) }}(\Omega)$ & 1.508 & 1.121 & 0.845 & 4.433 & 2.504 & 1.122 \\
\hline $\mathbf{R}_{\mathrm{S}(\text { sim. })}(\Omega)$ & 1.281 & 1.127 & 0.830 & 4.618 & 2.594 & 1.147 \\
\hline $\mathrm{C}_{\mathrm{DL}}(\mu \mathrm{F})$ & 1.134 & 2.137 & 8.096 & 1.145 & 4.529 & 5.574 \\
\hline $\mathbf{R}_{\mathrm{CT}}(\mathbf{\Omega})$ & 0.453 & 0.519 & 0.032 & 1.464 & 0.899 & 0.427 \\
\hline $\mathbf{Z}_{\mathbf{w}(1-\mathrm{R})}(\Omega)$ & 25.99 & 23.86 & 2.708 & 1770 & 7050 & 3119 \\
\hline $\mathbf{Z}_{\mathrm{w}(1-\mathrm{T})}(\Omega)$ & 0.061 & 0.063 & 0.075 & 0.416 & 3.598 & 18.28 \\
\hline $\mathbf{Z}_{\mathrm{w}(1-\mathrm{P})}(\Omega)$ & 0.600 & 0.601 & 0.311 & 0.763 & 0.761 & 0.709 \\
\hline
\end{tabular}

A simulated impedance plot for SPEEK $50 \%$ - $\mathrm{TiO}_{2}$ membranes for $30^{\circ} \mathrm{C}, 50^{\circ} \mathrm{C}$ and $80^{\circ} \mathrm{C}$ is shown in Figure 6 using circuit parameters estimated from the experimental impedance plot; these circuit parameters are given in Table 2. For all membranes the electrolyte resistances decreased with increasing temperature and with SD. $\mathrm{R}_{\mathrm{S}(\exp .)}$ and $\mathrm{R}_{\mathrm{S}(\mathrm{sim}) .}$ values were too close indicating a good fit, the highest coincidence occurs for higher temperatures. The SPEEK $63 \%-\mathrm{TiO}_{2}$ membrane showed lower resistivity than the SPEEK $50 \%-\mathrm{TiO}_{2}$ membrane, resulting in higher conductivity.

The level of agreement between experiment and simulation is quite satisfactory in terms of shape and distribution of frequencies, supporting the view that circuit equivalents are a meaningful way of representing the data. The results showed the best fitted were at $80^{\circ} \mathrm{C}$ (Figure 6).

\section{Conclusions}

Membranes based on SPEEK ( $w i t h \mathrm{SD}=63 \%$ and 50\%) and titanium oxide have been synthesized using the sol-gel process. The influence of sulfonation degree of the polymer on membrane properties was investigated. The ion exchange capacity increased with increasing of SD. The amorphous nature of composite membranes was confirmed by XRD studies. Water is coordinated to the sulfonic groups. The peak intensity which corresponds to the water loss and the loss of sulfonic groups increases with the increase of SD. For all membranes, the $\mathrm{R}_{\text {exp. }}$ and $\mathrm{R}_{\text {sim. }}$ values decreased with increasing of temperature and were too close indicating a good fit. The proton conductivity increased with increase of temperature and improves with increasing of sulfonation degree. The highest proton conductivity of $37.08 \mathrm{mS} . \mathrm{cm}^{-1}$ in water was obtained for the SPEEK $63 \%-\mathrm{TiO}_{2}$ membrane at $80^{\circ} \mathrm{C}$. Although still not reaching very high conductivity values, the SPEEK $63 \%-\mathrm{TiO}_{2}$ membranes shows the best performance in terms of thermal properties and proton conductivity, for this reason, we believe that this particular membranes have good prospects to be tested as electrolyte in PEMFC. The present investigation suggests measuring the conductivity of these composite membranes in ethanol and for higher temperatures.

\section{Acknowledgements}

The authors thank PNPD/CAPES for financial support granted to carry out this work.

\section{References}

1. Nikolic, V. M., Krkljes, A., Popovic, Z. K., Lausevic, Z. V., $\&$ Miljanic, S. S. (2007). On the use of gamma irradiation crosslinked PVA membranes in hydrogen fuel cells. Electrochemistry Communications, 11(9), 2661-2665. http:/ dx.doi.org/10.1016/j.elecom.2007.08.022.

2. Anis, A., Banthia, A. K., \& Bandyopadhyay, S. (2008). Synthesis $\&$ characterization of PVA/STA composite polymer electrolyte membranes for fuel cell application. Journal of Materials Engineering and Performance, 17(5), 772-779. http://dx.doi. org/10.1007/s11665-008-9200-1.

3. Di Vona, M. L., Ahmed, Z., Bellitto, S., Lenci, A., Traversa, E., \& Licoccia, S. (2007). SPEEK-TiO ${ }_{2}$ nanocomposite hybrid proton conductive membranes via in situ mixed sol-gel process. Journal of Membrane Science, 296(1-2), 156-161. http://dx.doi. org/10.1016/j.memsci.2007.03.037.

4. Kawaguti, C. A., Dahmouche, K., \& Gomes, A. de S. (2012). Nanostructure and properties of proton-conducting sulfonated poly(ether ether ketone) (SPEEK) and zirconia-SPEEK hybrid membranes for direct alcohol fuel cells: effect of the nature of swelling solvent and incorporation of heteropolyacid. Polymer International, 61(1), 82-92. http://dx.doi.org/10.1002/pi.3151.

5. Yang, T., Xu, Q., Wang, Y., Lu, B., \& Zhang, P. (2008). Primary study on double-layer membranes for direct methanol fuel cell. International Journal of Hydrogen Energy, 33(22), 6766-6771. http://dx.doi.org/10.1016/j.jhydene.2008.08.011.

6. Kobayashi, T., Rikukawa, M., Sanui, K., \& Ogata, N. (1998). Proton Conducting Polymers Derived from Poly (ether-ether ketone) and Poly (4-phenoxybenzoyl-1,4 phenylene). Solid State Ionics, 106(3-4), 219-225. http://dx.doi.org/10.1016/ S0167-2738(97)00512-2.

7. Zaidi, S. M. J. (2003). Polymer sulfonation: a versatile route to prepare proton-conducting membrane material for advanced technologies. Arabian Journal for Science and Engineering, 28(2B), 183-194.

8. Hou, H., Polini, R., Di Vona, M. L., Liu, X., Sgreccia, E., Chailan, J.-F., \& Knauth, P. (2013). Thermal crosslinked and nanodiamond reinforced SPEEK composite membrane for PEMFC. International Journal of Hydrogen Energy, 38(8), 3346-3351. http://dx.doi.org/10.1016/j.ijhydene.2012.12.019. 
9. Di Vona, M. L., Sgreccia, E., Donnadio, A., Casciola, M., Chailan, J. F., Auer, G., \& Knauth, P. (2011). Composite polymer electrolytes of sulfonated poly-ether-ether-ketone (SPEEK) with organically functionalized $\mathrm{TiO}_{2}$. Journal of Membrane Science, 369(1-2), 536-544. http://dx.doi.org/10.1016/j. memsci.2010.12.044.

10. Macdonald, J. R. (1987). Impedance spectroscopy-Emphasizing solid materials and systems. New York: Wiley-Interscience.

11. Macdonald, J. R., \& Potter, L. D. Jr (1987). A flexible procedure for analyzing impedance spectroscopy results: Description and illustrations. Solid State Ionics, 23(1), 61-79. http://dx.doi. org/10.1016/0167-2738(87)90068-3.
12. Carbone, A., Pedicini, R., Portale, G., Longo, A., D’llario, L., \& Passalacqua, E. (2006). Sulphonated poly(ether ether ketone) membranes for fuel cell aplication: thermal and structural characterization. Journal of Power Sources, 163(1), 18-26. http://dx.doi.org/10.1016/j.jpowsour.2005.12.066.

13. Dutra, J. C., Fo., Santos, T. R., \& Gomes, A. S. (2014). Nanostructured Polyelectrolytes Based on $\mathrm{SPEEK} / \mathrm{TiO}_{2}$ for Direct Ethanol Fuel Cells (DEFCs). Polimeros: Ciência e Tecnologia, 24, 43-48. http://dx.doi.org/10.4322/polimeros.2014.069.

Received: June 06, 2016

Revised: Dec. 01, 2016

Accepted: Jan. 05, 2017 